\title{
BMJ Open Comorbidity and healthcare use for individuals with CVD in the Ireland: a cross-sectional, population-based study
}

\author{
Karyn Morrissey
}

To cite: Morrissey K. Comorbidity and healthcare use for individuals with CVD in the Ireland: a cross-sectional, populationbased study. BMJ Open 2019;9:e025305. doi:10.1136/ bmjopen-2018-025305

- Prepublication history for this paper is available online. To view these files, please visit the journal online (http://dx.doi. org/10.1136/bmjopen-2018025305).

Received 12 July 2018 Revised 22 September 2018 Accepted 19 November 2018

Check for updates

(c) Author(s) (or their employer(s)) 2019. Re-use permitted under CC BY-NC. No commercial re-use. See rights and permissions. Published by BMJ.

European Centre for Environment and Human Health, University of Exeter Medical School, Exeter, Devon, UK

Correspondence to Dr Karyn Morrissey; K.Morrissey@exeter.ac.uk

\section{ABSTRACT}

Objective This study explores the factors associated with health service use for individuals with cardiovascular disease (CVD) and comorbidity in the Ireland.

Design Population-based cross-sectional survey.

Setting Nationally representative health and health service use survey from the 2010 Quarterly National Household Survey was analysed.

Primary outcome measures Four outcome variables were examined: no CVD, CVD only, CVD with CVD-related comorbidities and CVD with non-CVD-related comorbidity. Results of the 791 individuals reporting doctordiagnosed CVD, $77 \%$ had a second morbidity. Using type of healthcare coverage as a proxy for socioeconomic status, both CVD-related and non CVD-related comorbidity increases the use of health service usage substantially for individuals with CVD, particularly general practitioner services (8.47, $\mathrm{Cl} 4.49$ to 15.96 and $5.20, \mathrm{Cl} 2.10$ to 12.84 ) and inpatient public hospital care $(3.64, \mathrm{Cl} 2.93$ to 4.51 and $3.00, \mathrm{Cl} 2.11$ to 4.26 ).

Conclusion This study indicated that even when demographic and socioeconomic factors are controlled for, comorbidity significantly increases the risk of accessing health services for individuals with CVD.

\section{INTRODUCTION}

The WHO has projected that cardiovascular disease (CVD) alone will account for a quarter of global deaths by $2030 .{ }^{1}$ While WHO mortality estimates indicate that deaths associated with CVD in Ireland have decreased in the last decade ${ }^{2}$ and that disability adjusted life-years attributable to CVD are lower in Ireland than the European average, ${ }^{3}$ CVD burden comes from deaths and from those living with the disease. ${ }^{4}$ At the same time, the number of patients with CVD presenting with multiple coexistent diseases, or comorbidity is expected to increase. Comorbidity has important implications for healthcare use and related costs and represents a key future challenge for healthcare systems. ${ }^{56}$ To ensure the optimum organisation and delivery of healthcare services to treat comorbidity, an understanding (a) of the range of services used by individuals with comorbidity ${ }^{5}$ and (b) the

\section{Strengths and limitations of this study}

This study uses a representative population survey to examine health service use for people with comorbidities.

- The use of a healthcare coverage variable allows a socioeconomic analysis of health service usage for individuals with the same comorbidity profile.

- A limitation is that the dependent variables are based on self-reported, doctor diagnosed rather than clinical data.

socioeconomic profile of these service users is required. ${ }^{7-10} \mathrm{~A}$ frequently employed tool to understand health service use is Andersen's Behavioural Model of Health Service Use (BMHSU), ${ }^{11}$ which assumes that individuals' use of services is a function of their predisposition to use services (predisposing factors), factors that support or impede use (enabling factors), as well as their need for healthcare (needs-related factors). ${ }^{12-14}$ After presenting the prevalence figures of comorbidity for individuals with CVD, this paper uses Andersen's BMHSU to examine the impact of comorbidity in individuals with CVD on the use of general practitioner (GP), pharmacy and both public and private inpatient hospital care.

\section{DATA}

Collected by the Central Statistics Office (CSO), the Quarterly National Household Survey (QNHS) is a representative microlevel data set for the whole of Ireland. ${ }^{15}$ While the main purpose of the QNHS is the production of quarterly labour force estimates, in $2010 \mathrm{a}$ special module on health and health service utilisation was collected. This module was commissioned by a specially created health liaison group, which comprised experts in several fields of medical research and officials in the Department of Health. To assess healthcare use, the QNHS health module collected 


\begin{tabular}{|l|}
\hline \multicolumn{2}{|c|}{ Predisposing } \\
\hline \begin{tabular}{l} 
Socio- \\
demographic \\
- Age \\
\hline
\end{tabular} \\
\hline
\end{tabular}

\begin{tabular}{|c|c|}
\hline Enabling & Health Service Utilization \\
\hline $\begin{array}{ll}\text { Economic Means } \\
\text { - } \\
\text { - } & \text { Private Health } \\
& \text { Insurance }\end{array}$ & $\begin{array}{l}\text { - GP utilisation } \\
\text { - Pharmacy utilisation } \\
\text { - In-patient utilisation (public } \\
\text { \& private) }\end{array}$ \\
\hline
\end{tabular}

\begin{tabular}{|l|l|}
\hline \multicolumn{2}{|c|}{ Need Level } \\
\hline Doctor \\
diagnosed CVD \\
- & CVD only \\
- & CVD related \\
& comorbidities \\
- & CVD no \\
& related \\
& comorbidities \\
\hline
\end{tabular}

Figure 1 Andersen's behavioural model of health service use. CVD, cardiovascular disease; GP, general practitioner.

detailed information for different health services in the preceding 12 months including the number of times an individual used a GP service, pharmacy and inpatient hospital service (divided into public and private care). The number of nights in hospital (again, divided by public and private use) for inpatients is also collected. Containing data on 15673 individuals, ${ }^{15}$ the health module collected in Quarter 3, 2010 forms the basis of Anderson's BMHSU framework presented in this paper.

The individual characteristics used in this study, grouped by predisposing, enabling and need factors are presented in figure 1. In line with previous research on comorbidity, ${ }^{11-13}$ the predisposing factors used in this analysis include age and sex. With regard to enabling factors, this paper focuses on the economic means by which individuals may access healthcare in Ireland. Healthcare provision in Ireland is a mix of public and private provision, ${ }^{16}$ with eligibility for free healthcare means tested on an annual basis. In 2010 (the year of focus for this paper), individuals under a specific income level; all individuals over 70 years old and individuals with a number of long-term illnesses qualified for what is a medical card, which entitles them to free primary and acute health services in public hospitals. Then, rest of the population either paid the full economic cost for health services (GP, dentists, opticians and pharmacists) or a heavily subsided fee (hospital services) at the point of contact. ${ }^{16}$ Despite the heavily subsided fee associated with hospital care, and the majority of private insurance plans only covering hospital stays, half the Irish population paid for private health insurance during this time period. ${ }^{15}$ Given that all Irish citizens can avail of either free (medical card holders) or heavily subsidised inpatient care (the rest of the population), previous health
Table 1 Comorbidity of cardiovascular disease (CVD) with 13 other morbidities in the Ireland

\begin{tabular}{lccl}
\hline & $\begin{array}{l}\text { Comorbidity with } \\
\text { CVD (angina, } \\
\text { stroke, myocardial } \\
\text { infarction or heart } \\
\text { failure (\%)) }\end{array}$ & $\begin{array}{l}\text { CVD-related or non-related } \\
\text { morbidity }\end{array}$ \\
\hline Asthma & 6 & Non-CVD-related morbidity \\
\hline Bronchitis & 6 & Non-CVD-related morbidity \\
\hline Hypertension & 40 & CVD-related morbidity \\
\hline Cholesterol & 30 & CVD-related morbidity \\
\hline Cancer & 5 & Non-CVD-related morbidity \\
\hline Diabetes & 11 & Non-CVD-related morbidity \\
\hline Rheumatoid arthritis & 4 & Non-CVD-related morbidity \\
\hline Osteoarthritis & 11 & Non-CVD-related morbidity \\
\hline Osteoporosis & 3 & Non-CVD-related morbidity \\
\hline Depression/anxiety & 7 & Non-CVD-related morbidity \\
\hline Epilepsy & 1 & Non-CVD-related morbidity \\
\hline Urinary incontinence & 4 & Non-CVD-related morbidity \\
\hline Other condition & 10 & Non-CVD-related morbidity \\
\hline
\end{tabular}

research in Ireland has used coverage type as a proxy for socioeconomic status (SES) from the medical card (lowest), to the non-covered, to the privately insured (highest). ${ }^{17} 18$ This distinction has led researchers to use medical card ownership (lowest SES), non-covered (neither medical card or privately covered), privately insured (highest SES) as a proxy for income-based SES in the Ireland. ${ }^{17} 18$ Within this context, private health insurance, along with education level were included as the enabling factors within this analysis.

Regarding need factors, the QNHS Health and Health Service Use module contains four health conditions that taken together create a CVD variable: angina (chest pain on exertion due to inadequate blood flow to the heart muscle), stroke, myocardial infarction (heart attack) and heart failure. The QNHS data for 2010 contain 13 further morbidities that may be grouped as either CVD-related or non-CVD-related morbidities (table 1). In terms of the classification of the comorbidities as either CVD-related or CVD non-related, hypertension (40\%) and cholesterol $(30 \%)$ are the two diseases with the highest incidence of comorbidity with CVD (table 1). High levels of cholesterol and hypertension are well-documented risk factors for CVD and this is usually controlled with medication. These diagnoses are thus classified as CVD-related comorbidities. The other 11 morbidities (table 1) are grouped together as non-related CVD comorbidity. The next highest comorbid conditions are diabetes (11\%) and osteoarthritis (11\%). While diabetes often presents as comorbidity with CVD, ${ }^{12}$ as the health service provision associated with diabetes (metabolic) and CVD (vascular) are typically not integrated across and between different healthcare service, ${ }^{12}$ for the purpose of this health service focused paper, diabetes is classified as a non-related comorbidity. 
Table 2 Rate of doctor-diagnosed cardiovascular disease (CVD), CVD only, CVD-related morbidity and CVD nonrelated morbidity across the Irish Population

\begin{tabular}{|c|c|c|c|}
\hline & $\begin{array}{l}\% \text { General } \\
\text { population }\end{array}$ & $\begin{array}{l}\% \\
\text { Population } \\
\text { with CVD }\end{array}$ & Count \\
\hline CVD & 5.05 & & 791 \\
\hline CVD only & 1.14 & 22.5 & 179 \\
\hline $\begin{array}{l}\text { CVD+related morbidities } \\
\text { (hypertension+cholesterol) }\end{array}$ & 2.92 & 57.8 & 457 \\
\hline $\begin{array}{l}\text { CVD+non-related morbidities (all } \\
\text { others) }\end{array}$ & 0.99 & 19.6 & 155 \\
\hline
\end{tabular}

\section{METHODS}

This paper categorised the incidence of CVD-based morbidity as three mutually exclusive categories:CVD only, CVD-related comorbidity and non-CVD-related comorbidity. For the purpose of comparison, a fourth category is included, respondents stating they were never diagnosed with CVD. Descriptive statistics on individual demographic (predisposing factors), socioeconomic (enabling factors) and healthcare use (needs-based factors) measures are listed for individuals without CVD, CVD only, CVD-related comorbidity and CVD non-related comorbidity. As each of the CVD categories were coded as binary yes/no dummy variables logistic models were employed, adjusting for age, gender and educational level. The effect sizes as results of the logistic regression models were expressed as ORs and 95\% CI were calculated.

\section{Patient and public involvement}

This study is a secondary analysis of the QNHS for the Ireland provided by the CSO. Study design and development was not informed by patient input. We are not aware of the CSO plans for dissemination of results to study participants.

\section{RESULTS}

Examining the CVD dummy variables, $5 \%$ (791 individuals) of survey respondents reported having been diagnosed with CVD by a doctor (table 2). Of the individuals who had been diagnosed with CVD, $22.5 \%$ of individuals (179) were diagnosed with only CVD, $57.8 \%$ had a CVD-related comorbidity (hypertension and or cholesterol) and $38.6 \%$ had a non CVD-related comorbidity (one or more of the diagnosed categories outlined in table 1). These rates represent a $1 \%, 2.9 \%$ and $0.99 \%$ prevalence rate for CVD only, CVD-related comorbidity and non-CVD-related comorbidities across the Irish population (table 3).

\section{Descriptive statistics}

Table 3 presents descriptive statistics on individual demographic (predisposing factors) and socioeconomic (enabling factors) for the overall sample and for individuals without CVD, CVD only, CVD-related comorbidity and CVD non-related comorbidity. Examining the breakdown of coverage for participants in the QNHS, $19 \%$ of the sample had no coverage (paid at point of contact), $31 \%$ had a medical card (all public health services for free), $41 \%$ had private health insurance (covering private hospital care) and $8 \%$ had both a medical card and private health insurance. Individuals with CVD only were more likely to be male $(66 \%)$; however, no gender differences were observed for individuals with CVD-related comorbidities, more women $(52 \%)$ reported to have non-CVD-related morbidities. This finding is similar to previous research that has found that in the general population,

Table 3 Individual characteristics for individuals without cardiovascular disease (CVD), CVD only, CVD-related comorbidity and CVD non-related comorbidity

\begin{tabular}{|llllll}
\hline Variable & Overall sample & No CVD & CVD only & $\begin{array}{l}\text { CVD+related } \\
\text { morbidities }\end{array}$ & $\begin{array}{l}\text { CVD+non related } \\
\text { morbidities }\end{array}$ \\
\hline Male (\%) & 38 & 37 & 66 & 51 & 48 \\
\hline Age 18-24 (\%) & 5 & 99 & Less than 1\% & 0 & Less than 1\% \\
\hline Age 25-44 (\%) & 41 & 99 & Less than 1\% & Less than 1\% & Less than 1\% \\
\hline Age 45-64 (\%) & 33 & 95 & 1 & 3 & Less than 1\% \\
\hline Age 64+ (\%) & 21 & 84 & 3 & 9 & 3 \\
\hline Low education (\%) & 20 & 18 & 47 & 56 & 53 \\
\hline Medium education (\%) & 36 & 36 & 36 & 29 & 25 \\
\hline High education (\%) & 42 & 43 & 16 & 15 & 20 \\
\hline Education unspecified & 2.2 & 2 & 1 & Less than $1 \%$ & 3 \\
\hline No coverage (\%) & 19 & 20 & 11 & 6 & 4 \\
\hline Medical card (\%) & 31 & 30 & 52 & 62 & 60 \\
\hline Private insurance (\%) & 41 & 42 & 20 & 13 & 12 \\
\hline $\begin{array}{l}\text { Both medical card and private } \\
\text { health insurance (\%) }\end{array}$ & 8 & 8 & 18 & 19 & 25 \\
\hline
\end{tabular}


Table 4 Mean healthcare use measures for individuals without cardiovascular disease (CVD), CVD only, CVD-related comorbidity and CVD non-related comorbidity

\begin{tabular}{|c|c|c|c|c|}
\hline Variable & No CVD & CVD only & $\begin{array}{l}\text { CVD+related } \\
\text { morbidities }\end{array}$ & $\begin{array}{l}\text { CVD+non-related } \\
\text { morbidities }\end{array}$ \\
\hline General practitioner & 77 & 93 & 98 & 97 \\
\hline Pharmacy & 40 & 42 & 45 & 44 \\
\hline Inpatient public & 9 & 27 & 32 & 32 \\
\hline Inpatient private & 2 & 2 & 6 & 5 \\
\hline \multicolumn{5}{|l|}{ Doctor } \\
\hline No coverage & 16 & 10 & 6 & 3 \\
\hline Medical card & 33 & 53 & 62 & 60 \\
\hline Private health insurance & 41 & 18 & 13 & 12 \\
\hline Both medical card and private health insurance & 9 & 19 & 19 & 25 \\
\hline \multicolumn{5}{|l|}{ Pharmacy } \\
\hline No coverage & 17 & 12 & 8 & 1 \\
\hline Medical card & 32 & 49 & 64 & 68 \\
\hline Private health insurance & 43 & 19 & 11 & 12 \\
\hline Both medical card and private health insurance & 8 & 20 & 17 & 19 \\
\hline \multicolumn{5}{|l|}{ Inpatient public } \\
\hline No coverage & 13 & 15 & 5 & 0 \\
\hline Medical card & 37 & 38 & 61 & 61 \\
\hline Private health insurance & 37 & 21 & 14 & 14 \\
\hline Both medical card and private health insurance & 13 & 27 & 20 & 24 \\
\hline \multicolumn{5}{|l|}{ Inpatient private } \\
\hline No coverage & 3 & 0 & 0 & 0 \\
\hline Medical card & 6 & 0 & 3 & 0 \\
\hline Private health insurance & 66 & 50 & 27 & 71 \\
\hline Both medical card and private health insurance & 25 & 50 & 69 & 28 \\
\hline
\end{tabular}

there were more women than men with comorbidity. ${ }^{7} \mathrm{~A}$ clear age gradient is observed with younger individuals reporting the lowest rates of all morbidity categories, with the age category over 65 years old see a large increase in individuals reporting CVD-related (9\%) and non-related (3\%) comorbidities.

With regard to education level, individuals with high education had the lowest rates of all morbidity categories. Individuals with CVD-related comorbidities (81\%) and non-CVD-related morbidities (85\%) have higher rates of medical card eligibility compared with individuals without CVD (38\%) and individuals with CVD only $(70 \%)$. In terms of healthcare coverage, individuals with private health insurance have the highest rates of no CVD, while individuals with medical cards report the highest rates for each morbidity category. Importantly, people without either a medical or private health insurance have the lowest rates of each morbidity. A cross-tabulation of coverage by age class indicates that this may be related to the age profile of individuals with the majority of the sample without either a medical card of private health insurance aged between 18 and 44 years old.
Table 4 presents the percentage of individuals with each of the four morbidity categories that accessed GP services, pharmacies and inpatient hospital services in both public and private hospitals. Table 4 also presents the percentage of individuals by morbidity, health service usage and type of healthcare coverage. Examining morbidity by health service accessed first, with the exception of having visited a pharmacy, the descriptive statistics show that there is a clear gradient between not being diagnosed with CVD and having CVD, CVD-related morbidities and CVD non-related comorbidities for each health service. Individuals with CVD, CVD-related, and CVD non-related morbidities report much higher GP and public inpatient hospital use. Using health coverage type as a proxy for SES, table 4 shows that individuals with a medical card and CVD, CVD-related and CVD non-related morbidities accessed GP, pharmacy and inpatient hospital care compared with all other coverage types. As expected, the individuals with private health insurance had the highest levels of private inpatient hospital care. 
Table 5 Effect of comorbidity of individuals with cardiovascular disease (CVD) on healthcare use adjusted for age, gender, private hospital care and educational level (Cl presented within brackets)

\begin{tabular}{lllcc}
\hline & No CVD & CVD & CVD-related & CVD non-related \\
\hline General practitioner & 0.17 & 2.69 & 8.47 & 5.20 \\
& $(0.12$ to 0.26$)$ & $(1.48$ to 4.90$)$ & $(4.49$ to 15.96$)$ & $(2.10$ to 12.84$)$ \\
Pharmacy & 0.73 & 1.28 & 1.38 & 1.24 \\
& $(0.62$ to 0.85$)$ & $(0.94$ to 1.74$)$ & $(1.14$ to 1.68$)$ & $(0.90$ to 1.72$)$ \\
Inpatient public & 0.26 & 2.69 & 3.64 & 3.00 \\
& $(0.22$ to 0.31$)$ & $(1.91$ to 3.80$)$ & $(2.93$ to 4.51$)$ & $(2.11$ to 4.26$)$ \\
Inpatient private & 0.60 & 0.65 & 2.09 & 1.47 \\
& $(0.41$ to 0.87$)$ & $(0.23$ to 1.80$)$ & $(1.36$ to 3.21$)$ & $(0.67$ to 3.22$)$ \\
\hline
\end{tabular}

\section{Logistic regression model}

Incorporating predisposing, enabling and needs-based factors within a set of logistic models, table 5 indicates that individuals without CVD had a strong significant negative association with health service use in the previous 12 months, GP visits $(0.17$, CI 0.12 to 0.26$)$, pharmacy visits $(0.73$, CI 0.62 to 0.85$)$, inpatient public hospital care (0.26, CI 0.41 to 0.87$)$ and inpatient private hospital care $(0.60$, CI 0.41 to 0.87$)$. Examining individuals with CVD only and CVD-based comorbidities, individuals with a CVD-related comorbidity had the largest increased risk for accessing GP services (8.47, CI 4.49 to 15.96) and pharmacy visits (1.38, CI 1.14 to 1.68$)$. For both of these health services, having a comorbidity, both related and non-related had significantly higher OR compared with CVD only. For public inpatient services, having CVD, a CVD-related, and CVD non-related comorbidity were significantly associated with a 2.69 (CI 1.91 to 3.80 ), 3.64 (CI 2.93 to 4.51 ) and 3.00 (CI 2.11 to 4.26 ) increased risk of having used these services in the previous 12 months. For private inpatient services, having CVD only has a negative, but insignificant association with service usage $(0.65,0.23$ to 1.80$)$. Individuals with CVD-related and CVD non-related comorbidities had a 2.09 (CI 1.36 to 3.21 ) and 1.47 (CI 0.67 to 3.22) risk of having used these services in the previous 12 months.

\section{DISCUSSION}

Data on the prevalence of key comorbidities and indicators of healthcare use are useful in assessing current and future health service needs for individuals with CVD. This paper used Anderson's BMHSU to examine the impact of CVD-based comorbidities on health service use in Ireland. Of the 791 individuals reporting doctor-diagnosed CVD, $77 \%$ had additional morbidities. High levels of cholesterol and hypertension are well-documented risk factors for CVD and this is usually controlled with medication and were therefore classed as CVD-related comorbidities. However, $11 \%$ and $11 \%$ of participants with CVD reported having being doctor diagnosed with diabetes and osteoarthritis, respectively. These results indicate that for individuals with CVD non-vascular comorbidities are important use drivers as vascular comorbidities. Similar to international research, ${ }^{7-10}$ the descriptive statistics presented show a clear socioeconomic gradient in terms of the prevalence of CVD and CVD plus comorbidities, with individuals with higher levels of education and private health insurance having lower levels of CVD and CVD-based comorbidities. In contrast, individuals with medical cards have higher levels of CVD and CVD-based comorbidities. The descriptive statistics on health service use indicated that individuals with CVD, CVD-related and CVD non-related morbidities report much higher GP and public inpatient hospital use. Examining use by health coverage type reconfirms the social gradient, individuals with a medical card and CVD, CVD-related and CVD non-related morbidities accessed GP, pharmacy and inpatient hospital care compared with all other coverage types. This indicates that in the Ireland, individuals with lower SES need to use more healthcare services compared with individuals with higher SES for the same doctor-diagnosed morbidities.

Controlling for demographic and socioeconomic factors via a logistic regression model, this analysis found that individuals with CVD non-related comorbidities had the largest significant association with GP visits and inpatient treatment in both public and private hospitals. High GP usage indicates that individuals with CVD and comorbidities are being managed in the primary care sector; these results indicate a high clinical burden particularly for individuals with comorbidities on general practices. As a result of different factors, including ageing populations and advances in medical care and public health policy, the number of individuals presenting with more than one morbidity is expected to increase. Furthermore, the comorbidity of non-related CVD-based morbidities such as osteoarthritis indicate that primary care services are already dealing with patients with complex health demands and that adequate training and resources is required.

These results demonstrate that (1) health service usage increase significantly for individuals with comorbidities; (2) there is a clear socioeconomic gradient in the prevalence of CVD and CVD-based comorbidities in Ireland 
and (3) individuals with lower SES status accessed more health services compared with individuals with higher SES. Although this paper did not conduct a formal health-economic analyses, our data suggest that lower SES as measured by education and health coverage type is likely to be associated with substantial variation in the costs of caring for people with CVD and a further morbidity. From a public health policy perspective, in addition to the beneficial effects of not having a range of morbidities on an individual's quality of life, the prevention of comorbidity can also curb the growing demands for healthcare, particularly among high-risk groups. ${ }^{78}$

\section{Study limitations}

Limitations of the study need to be considered in interpreting the results. First, this study is based on a representative sample of the Irish population; however, the data are old and relates to 2009/2010. However, an analysis of this data is still important as while mortality due to CVD is decreasing, the burden of CVD and comorbidity is increasing, thus the data presented here are indicative of an upward trend in the healthcare service needs of the Irish population. Second, the dependent variables used in this study are based on self-reported doctor diagnosis rather than clinical records. It is important to note that there may be limitations on using a dependent variable that is self-reported, with regard to respondent memory and accuracy of diagnosis. However, this study believed that to understand the health service usage patterns and socioeconomic profile of individuals with a CVD-based comorbidity, a data set with representative sample of the Irish population was more appropriate than a clinical data set. Finally, as with as with all health analysis using survey data, survival bias needs to be noted.

\section{Contributors All work was completed by KM.}

Funding The authors have not declared a specific grant for this research from any funding agency in the public, commercial or not-for-profit sectors.

Competing interests None declared.

Patient consent for publication Not required.

Ethics approval This data used anonymised secondary data that was obtained under a data sharing agreement with ISSDA (University College Dublin), no ethics approval was required by the author.

Provenance and peer review Not commissioned; externally peer reviewed. Data sharing statement № additional data are available.
Open access This is an open access article distributed in accordance with the Creative Commons Attribution Non Commercial (CC BY-NC 4.0) license, which permits others to distribute, remix, adapt, build upon this work non-commercially, and license their derivative works on different terms, provided the original work is properly cited, appropriate credit is given, any changes made indicated, and the use is non-commercial. See: http://creativecommons.org/licenses/by-nc/4.0/.

\section{REFERENCES}

1. World Health Organisation. A global brief on hypertension: Silent killer, global public health crisis. Geneva, Switzerland: World Health Organization, 2013.

2. World Health Organisation. Why the HIV epidemic is not over. http:// www.who.int/countries/irl/en/ (Accessed 21 Sep 2018).

3. European Heart Network. European cardiovascular disease statistics. 2017.

4. Bhatnagar P, Wickramasinghe K, Wilkins E, et al. Trends in the epidemiology of cardiovascular disease in the UK. Heart. 2016 Jul 26. Heartjnl 2016.

5. Guthrie B, Payne K, Alderson P, et al. Adapting clinical guidelines to take account of multimorbidity. BMJ: British Medical Journal (Online), 2012:345.

6. Stange KC. Challenges of managing multimorbidity. Ann Fam Med 2012;10:2-3.

7. Barnett K, Mercer SW, Norbury M, et al. Epidemiology of multimorbidity and implications for health care, research, and medical education: a cross-sectional study. Lancet 2012;380:37-43.

8. Morrissey K, Espuny F, Williamson P. A multinomial model for comorbidity in England of long-standing cardiovascular disease, diabetes and obesity. Health Soc Care Community 2016;24:717-27.

9. Mercer SW, Watt GCM. The inverse care law: clinical primary care encounters in deprived and affluent areas of Scotland. The Annals of Family Medicine 2007;5:503-10.

10. Schäfer I, Hansen H, Schön G, et al. The influence of age, gender and socio-economic status on multimorbidity patterns in primary care. First results from the multicare cohort study. BMC Health Serv Res 2012;12:89.

11. Andersen R, Newman JF. Societal and individual determinants of medical care utilization in the United States. Milbank Mem Fund Q Health Soc 1973;51:95-124

12. Struijs JN, Baan CA, Schellevis FG, et al. Comorbidity in patients with diabetes mellitus: impact on medical health care utilization. BMC Health Serv Res 2006;6:1-9.

13. Fleury MJ, Grenier G, Bamvita JM, et al. Comprehensive determinants of health service utilisation for mental health reasons in a Canadian catchment area. Int J Equity Health 2012;11:20.

14. Heider $\mathrm{D}$, Matschinger $\mathrm{H}$, Müller $\mathrm{H}$, et al. Health care costs in the elderly in Germany: an analysis applying Andersen's behavioral model of health care utilization. BMC Health Serv Res 2014;14:71.

15. Office CS. Quarterly national household survey: special module on health and health service utilisation. Ireland: Dublin: Central Statistics Office, 2010.

16. Wren MA, Keegan C, et al. Projections of demand for healthcare in Ireland, 2015-2030: First report from the Hippocrates Model. Ireland: Economic and Social Research Institute, 2017.

17. Smith S, Normand $\mathrm{C}$. Analysing equity in health care financing: a flow of funds approach. Soc Sci Med 2009;69:379-86.

18. Keegan $C$, Smith S. The length of stay of in-patient stroke discharges in Irish acute hospitals. The Economic and Social Review 2013;44:351-70. 